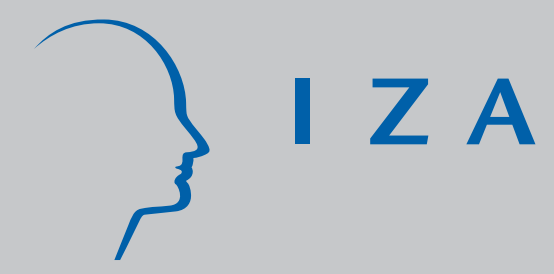

IZA DP No. 3635

Being Born Under Adverse Economic Conditions Leads to a Higher Cardiovascular Mortality Rate Later in Life: Evidence Based on Individuals Born at Different Stages of the Business Cycle

Gerard J . van den Berg

Gabriele Doblhammer-Reiter

Kaare Christensen

August 2008 


\title{
Being Born Under Adverse Economic Conditions Leads to a Higher Cardiovascular Mortality Rate Later in Life: Evidence Based on Individuals Born at Different Stages of the Business Cycle
}

\author{
Gerard J. van den Berg \\ VU University Amsterdam, IFAU Uppsala, \\ Netspar, CEPR, IFS and IZA \\ Gabriele Doblhammer-Reiter \\ University of Rostock \\ and Max Planck Institute for Demographic Research \\ Kaare Christensen \\ University of Southern Denmark, Danish Twin Registry \\ and Danish Aging Research Center
}

Discussion Paper No. 3635

August 2008

IZA

P.O. Box 7240

53072 Bonn

Germany

Phone: +49-228-3894-0

Fax: +49-228-3894-180

E-mail: iza@iza.org

Any opinions expressed here are those of the author(s) and not those of IZA. Research published in this series may include views on policy, but the institute itself takes no institutional policy positions.

The Institute for the Study of Labor (IZA) in Bonn is a local and virtual international research center and a place of communication between science, politics and business. IZA is an independent nonprofit organization supported by Deutsche Post World Net. The center is associated with the University of Bonn and offers a stimulating research environment through its international network, workshops and conferences, data service, project support, research visits and doctoral program. IZA engages in (i) original and internationally competitive research in all fields of labor economics, (ii) development of policy concepts, and (iii) dissemination of research results and concepts to the interested public.

IZA Discussion Papers often represent preliminary work and are circulated to encourage discussion. Citation of such a paper should account for its provisional character. A revised version may be available directly from the author. 


\section{ABSTRACT}

\section{Being Born Under Adverse Economic Conditions Leads to a Higher Cardiovascular Mortality Rate Later in Life: Evidence Based on Individuals Born at Different Stages of the Business Cycle*}

We connect the recent medical and economic literatures on the long-run effects of early-life conditions, by analyzing the effects of economic conditions on the individual cardiovascular (CV) mortality rate later in life, using individual data records from the Danish Twin Registry covering births since the 1870 s and including the cause of death. To capture exogenous variation of conditions early in life we use the state of the business cycle around birth. We find a significant negative effect of economic conditions early in life on the individual CV mortality rate at higher ages. There is no effect on the cancer-specific mortality rate. From variation within and between monozygotic and dizygotic twin pairs born under different conditions we conclude that the fate of an individual is more strongly determined by genetic and household-environmental factors if early-life conditions are poor. Individual-specific qualities come more to fruition if the starting position in life is better.

JEL Classification: I10, J14, C41, H75, E32, J10, N33, N13, I12, I18

Keywords: longevity, genetic determinants, health, recession, life expectancy, cardiovascular disease, cancer, lifetimes, fetal programming, cause of death, developmental origins

Corresponding author:

Gerard J. van den Berg

Department of Economics

VU University Amsterdam

De Boelelaan 1105

1081 HV Amsterdam

The Netherlands

E-mail: gjvdberg@xs4all.nl

\footnotetext{
* We thank Angus Deaton, Hans Christian Johansen, Adriana Lleras-Muney, Bernard van Praag, Andreas Wienke, and participants at seminars at St. Gallen University, VU University Amsterdam, Groningen University, and INSEE-CREST, and conferences in Mölle/Lund and Berlin, for helpful comments. We also thank Axel Skytthe for help with the Danish twin registry data and Ingrid Henriksen, Mette Bjarnholt and Mette Erjnaes for help with the Danish historical time series data.
} 


\section{Introduction}

In many scientific disciplines, the interest in long-run effects of early-life conditions has been strongly increasing during the past years. In medical science, the "Developmental Origins" and "Fetal Programming" hypotheses, which state that certain diseases at high ages can be caused by deprivation in utero or around birth, has been confirmed by a range of studies, in particular for cardiovascular diseases (CVD) as outcome (see references below). More generally, the search for early origins as causes of CVD later in life has become an important focal point of research in medical science. In epidemiology and demography, various indicators of early-life conditions have been found to be associated with health and mortality later in life. At the same time, economists and sociologists are increasingly interested in the importance of parental income and socio-economic status as explanations for health later in life. ${ }^{1}$

In this paper we aim to combine the medical/epidemiological and economic contributions on long-run effects of early-life conditions, by analyzing the causal effect of economic conditions around birth on the individual rate of mortality due to cardiovascular diseases much later in life. For this purpose we use individual twin register data covering multiple birth cohorts, containing the dates of birth and death and the cause of death.

In each of the above-mentioned disciplines, the empirical evidence often replies on indicators of early-life conditions for which it is questionable that they are exogenous causal determinants of health later in life. An association between such an indicator and health later in life then does not necessarily imply the presence of a causal effect of early-life conditions. Instead, the indicator and the health outcome may be jointly affected by related unobserved determinants. Consider for example parental income or wealth at birth. To some extent, this is determined by unobserved factors that also directly affect the morbidity and

\footnotetext{
${ }^{1}$ Surveys and meta-studies of the epidemiological and medical evidence of associations of birth weight indicators and CVD later in life have been published in Poulter et al. (1999), Rasmussen (2001), and Huxley et al. (2007). The survey in Eriksson (2007) also focuses on medical early-life indicators measured after birth. Gluckman, Hanson and Pinal (2005) and Barker (2007) give overviews of the underlying medical mechanisms. Some studies also point at long-run effects on other diseases like type-2 diabetes and breast cancer. Pollitt, Rose and Kaufman (2005) provide a survey and meta-study of the "life course" literature on causal pathways in which early-life socio-economic status (SES) is associated with CV morbidity and mortality later in life. Galobardes, Lynch and Davey Smith (2004) survey studies on early-life SES and cause-specific mortality in adulthood. See also Case, Fertig and Paxson (2005) and Case, Lubotsky and Paxson (2002) and references therein, for influential studies focusing on economic household conditions early in life.
} 
mortality of individuals at higher ages. An association between parental income at birth and longevity may then be due to the fact these have shared determinants. Similar problems arise with the use of birth weight or weight at gestational age, as has been acknowledged in the medical and epidemiological literature. These measures depend on genetic determinants, and it is not clear to what extent these can be controlled for by conditioning on additional covariates (see arguments made in e.g. the surveys of Poulter et al., 1999, Rasmussen, 2001, Huxley et al., 2007, Lawlor, 2008, and also Ben-Schlomo, 2001, and Järvelin et al., 2004).

We deal with this methodological problem by using the state of the business cycle at early ages as indicators of early-life conditions. Transitory macroeconomic conditions during pregnancy of the mother and early childhood are unanticipated and exogenous from the individual point of view, and they affect income for many households. In a recession, the provision of sufficient nutrients and good living conditions for infants and pregnant women may be hampered, and the stress level in the household may be higher than otherwise. It can be argued that the only way in which the indicators can plausibly affect high-age mortality is by way of the individual early-life conditions (in Section 2 we address this in more detail). This means that such indicators do not give rise to endogeneity and simultaneity biases. The approach to use transitory features of the macro environment as indicators of individual early-life conditions, rather than unique characteristics of the newborn individual or his family or household, has recently become popular. Doblhammer (2004) uses month of birth, whereas other studies compare individuals born during extreme events like epidemics, wars, and famines, to those born outside of the periods covered by these events (see e.g. Almond, 2002). Bengtsson and Lindström (2000, 2003) use the transitory component of the local price of rye around birth and the local infant mortality rate. Van den Berg, Lindeboom and Portrait (2006) use the state of the business cycle at early ages as determinants of all-cause individual mortality using Dutch data on births in 1815-1902. Cutler, Miller and Norton (2007) use the Great Depression in the Dust Bowl area in the US. ${ }^{2}$ One may argue that results based on extreme events are hard to extrapolate because long-run effects may be non-linear in the hardships early in life. This makes business cycles and

\footnotetext{
${ }^{2}$ They do not find evidence of a long-run effect on CVD among those who survive until 1992, from interviews that were held every 2 years since 1992. One explanation put forward by the authors is that deaths due to CVD between interview dates may be underreported. This suggests that registered death causes may be more informative on long-run CV effects than self-reported health statuses. Another explanation put forward is that there may have been sufficient opportunities for consumption smoothing, and sufficient relief payments, to mitigate adverse effects of this recession.
} 
seasons potentially more useful as indicators of early-life conditions than severe epidemics or famines. Moreover, the latter type of events may lead to high infant mortality and dynamic selection of the fittest in the cohort, which complicates the statistical analysis. ${ }^{3}$

The Danish Twin Registry data we use in the present paper are uniquely equipped for our purposes, because (i) they contain the exact dates of birth and death, (ii) they cover birth cohorts over a rather large time frame, covering many transitory fluctuations in the economy, (iii) in each birth cohort that we consider, a sufficiently large fraction of individuals has been observed to die, and (iv) they contain the cause of death. Other data sets like those in the Human Mortality Database only contain death cause information for recent birth cohorts in which most individuals are still alive (see e.g. Andreev, 2002, for Danish data). Alternatively, birth dates in data sets are time-aggregated into intervals covering more than a year, which is fatal for our approach, or they only contain a small number of birth cohorts around some extreme event, and/or they contain health outcomes but not mortality outcomes.

A fifth and major additional advantage of the twin data is that the observation of zygosity of the twin pair allows us to assess the relative importance of genetic factors, shared environmental factors, and individual-specific factors, as determinants of CV mortality and longevity. More specifically, it allows us to assess to what extent the relative importance of family/household-specific and individual-specific determinants depends on the business cycle at birth, and thus on economic conditions early in life. From this we can infer whether the fate of an individual born under adverse conditions is more strongly shaped by the family background vis-à-vis the individual's own characteristics than if (s)he were born under better conditions. ${ }^{4}$ As above, we address the presence of such interactions by using exogenous indicators of economic conditions early in life, which is a methodological advantage over the use of family income or social status as an interacting variable for genetic determinants.

One may argue that a twin birth poses a heavier burden on the household than the birth of a single child. This merely means that the exogenous variation in early-life conditions will be expressed more strongly through twins, but it

\footnotetext{
${ }^{3}$ For clarity, note that we are not concerned with instantaneous "period" effects of recessions on health. Ruhm (2000) shows that recessions may have protective instantaneous health effects in modern economies.

${ }^{4}$ Black, Devereux and Salvanes (2007) exploit differences in twins' within-pair birth weight to detect long-run effects of birth weight on economic outcomes. Our data do not provide observations of birth weight, and more in general we do not observe within-pair differences in early-life conditions.
} 
obviously does not affect the existence or non-existence of the causal effect from these conditions. In this sense, a twinbirth in a mild recession should have the same effect as a single birth in a sufficiently severe recession. Another issue is whether the composition of the (twin) birth cohorts systematically varies over the business cycle. We investigate this by examining fluctuations in birth rates and twinning rates, and by using additional survey data on the composition.

Long-run effects of economic conditions early in life may work through nutrition, disease exposure, household stress levels, and the level of living comfort in the household. We shed some light on these by studying the importance of the timing of the macro fluctuations around the year of birth and by interacting the effects with regional indicators and the degree of urbanization.

The Danish twin data have been used by many other studies. These often exploit or study the similarities between MZ and DZ twins (see Skytthe et al., 2002, and Harvald et al., 2004, for overviews). Christensen et al. (1995, 2001) compare patterns of mortality across age and cohort intervals in the twin data to the corresponding intervals in the general population, and they conclude that among adults the patterns are usually the same. Wienke et al. (2001) replicate this for coronary heart disease, and they reach the same conclusion. This suggests that twins are not necessarily different from single births, when it comes to the mortality distribution at higher ages, which supports the relevance of our analyses.

Knowledge on the magnitude of long-run effects may have important policy implications. If being born under certain adverse conditions increases the individual CV mortality rate in the long run (and therefore has a negative effect on longevity) then the value of life is reduced for those affected, and this would increase the benefits of supportive policies for such groups of individuals. The long-run effect of early-life conditions on the mortality rate may be smaller than the instantaneous effect of current conditions, but the former exert their influence over a longer time span. Moreover, the presence of a time interval between infancy and the manifestation of the effect implies that there is a scope for identification and treatment of the individuals at risk. Specifically, young individuals born under adverse conditions can be targeted for a screening of CVD markers and predictors, and those who have unfavorable test values are amenable to preventive intervention. Note that screening and preventive intervention policies can also be justified by proven associations between risk factors like birth weight and parental income on the one hand, and CV mortality on the other.

The analysis in this paper also allows for a more modest motivation, namely the study of whether individuals born in a recession have a higher CV mortality 
rate later in life. If one is concerned about health inequality due to variation in the state of the business cycle at birth, then evidence of such a long-run effect provides a rationale for macroeconomic stabilization policy. Moreover, it may then be sensible to target policy at infants born in recessions. Their mortality later in life could be significantly reduced if their conditions are improved upon, for example by monitoring their health shortly after birth and by providing food, housing, and health care.

It should be emphasized that living conditions in Denmark around 1900 were relatively good in comparison to most other countries at the time and in comparison to many developing countries today. Life expectancy was the highest in the world (Johansen, 2002a). Health insurance coverage was high. Denmark arguably had the best health care system in the world in terms of well-being of mothers and infants (see Løkke, 2007, for a detailed survey). Insurance societies paid out sickness absence benefits to employed workers who had fallen ill. In general, there was an extensive poor relief system.

Nevertheless, one may conjecture that nutritional conditions in Denmark around 100 years ago were different from current conditions. In this respect it is important to point out that recent medical research has shown that not just fetal malnourishment is associated with long-run effects on CVD outcomes, but, more in general, that discrepancies between early-life conditions in utero and shortly after birth on the one hand, and later lifestyle on the other hand, lead to long-run effects on CVD outcomes (see e.g. Mogren et al., 2001, and Holemans, Caluwaerts and André Van Assche, 2002; see also Fogel, 1997, for an overview). In this sense, our study is also of importance for modern societies. Individuals born in low-income household who have very high nutritional intakes later in life may be particularly at risk for adverse CVD outcomes at higher ages. ${ }^{5}$

For current developing countries, which in certain aspects could be regarded as similar to or worse off than Denmark in the period evaluated in the present paper, the existing literature has focused on inequalities in infant and child mortality by household socioeconomic status, since there are typically no long run data registers (see Sastry, 2004). In this sense, our paper aims to complement these studies by studying long run mortality effects.

The paper is organized as follows. Section 2 presents the data and discusses variables that we use in the analyses. Section 3 displays readily observable data

\footnotetext{
${ }^{5}$ Note that the virtual disappearance of infant mortality implies that those who would have died if born under adverse conditions in the nineteenth century nowadays survive into adulthood. This can be seen as a factor that contributes to the potential relevance of long-run effects in modern societies.
} 
features that confirm the existence of the causal mechanisms that we are interested in. Section 4 describes the formal empirical analyses and the results. In this section we also examine whether the composition of mortality determinants among newborns and newborn twins varies over the cycle in a systematic way. Section 5 concludes.

\section{The data}

\subsection{Individual records from the Twin Registry}

Our individual data records are derived from the Danish Twin Registry. This registry has been created over decades in an attempt to obtain a comprehensive sample of all same-sex twins born since 1870 and surviving as twins until at least age 6 (and it also includes many different-sex twins). We refer to studies listed in Section 1 for detailed descriptions of the registry and the way it has been collected. A number of factors determine the selection that we use for the empirical analysis. Most importantly, we restrict ourselves to twins for whom sufficient information is available on the most important variables. A crucial aspect is that most individuals born in the chosen birth interval should be observed to die. In recent cohorts, almost all individuals are still alive, so that these would merely add right-censored drawings from the lifetime duration distribution. At the same time, it is not clear whether the underlying longevity determinants exert a similar effect as in earlier cohorts, because the increasing welfare in later years may have led to a dampening of the effect of a recession and other economic hardships on a household's food provision. This implies that we should consider earlier cohorts.

In the late 19th century, Denmark had about 2.3 million inhabitants, of whom about 0.35 million lived in Copenhagen. The economy had a large agricultural sector, accounting for almost half of GDP and the workforce, but this sector itself had to some extent already been industrialized. The economy was open, and export volume and the business cycle were sensitive to events in Britain. The country faced substantial GDP growth after 1870 (see e.g. Statistics Denmark, 1902, Christensen, 1985, Johansen, 1985, Henriksen and O'Rourke, 2005, and Greasley and Madsen, 2006, for details of the Danish economy in the late 19th century). For our purposes, it is important to point out that in 1907 unemployment benefits were introduced in Denmark, with the explicit objective to dampen adverse effects of the business cycle on the economic well-being of the Danish population. To keep the heterogeneity in early-life societal conditions within bounds, we therefore restrict attention to those born before 1907. Among 
the cohorts born before 1910, the fraction of twins per birth year with known zygosity increases with the birth year, so adding some cohorts born shortly after 1907 to samples with known zygosities would result in samples in which the later-born cohorts dominate. In any case, it turns out that our results are not sensitive with respect to small changes in the cut-off year.

We restrict attention to same-sex twin pairs with known zygosity, for which both twins survive until at least January 1, 1943. This is because for this group the highest efforts have been made to collect the death cause and date. In the registry, the death cause is unobserved for all deaths before 1943, and the death cause and date are unobserved for most deaths of different-sex twin pairs or twin pairs with unknown zygosity after 1943. The restriction to survival until 1943 is not a serious limitation in the sense that we are particularly interested in mortality at higher ages. Finally, we delete births in 1870-1872 because the macro-economic indicator (see below) seems to be unreliable for those years. The latter reduces the sample size by only $2 \%$.

As a result, we use a sample of all 6050 same-sex twin members with known zygosity, born in 1873-1906, for which both twins survive until at least January 1, 1943. The birth and death dates and the resulting individual lifetime durations are observed in days. The observation window ends on January 6, 2004, so individuals still alive then $(0.4 \%)$ have right-censored durations. Table 1 gives some sample statistics. We should emphasize that the death date is observed for more than $95 \%$ of the individuals in our sample, and for $99 \%$ of the latter we also observe the death cause. The death cause is classified according to the ICD system, versions 5-8, at the 3-digit level. These are grouped into 12 categories, which are subsequently grouped into our 3 main death causes: "cardiovascular" (death due to cardiovascular malfunctions or diseases, including apoplexy) ${ }^{6}$ "cancer" (death due to malignant neoplasms or congenital malformations - the latter concerns less than $0.1 \%$ of our sample) and "other" (including death due to tuberculosis, other infectious diseases, diseases of the respiratory, digestive or uro-genital system, suicide, or accidents). The first of these three death causes is the most prominent in our sample. Its frequency decreases as a function of the birth year. Among those born in the 1870s, $60 \%$ are observed to die from CVD, whereas among those born in the $1900 \mathrm{~s}$, this is $50 \%$. Note that the former group contains more elderly individuals due to the requirement of survival until $1943 .^{7}$

\footnotetext{
${ }^{6}$ In the "cardiovascular" category, the most common 3-digit death causes are cerebral haemorrhage, acute myocardial infarction, chronic ischemic heart disease, arteriosclerotic heart disease including coronary disease, and acute but ill-defined cerebrovascular disease.

${ }^{7}$ See National Board of Health, 1983, Johansen, 1985, and Andreev, 2002, for detailed
} 
When we select explanatory variables for individual mortality from the individual records, we restrict attention to characteristics that are realized at birth as opposed to later in life, for the reason that the latter may be endogenous or confounded. In particular, we do not include variables on life events like marriage.

The information on the location of birth is two-dimensional and aggregated. We observe in which of the four main parts of Denmark the individual is born (Copenhagen, Zealand excluding Copenhagen, Funen, or Jutland, where it should be noted that the islands of Lolland and Bornholm are included in Zealand, and Jutland is the only part of the country belonging to mainland Europe), and we also observe a crude indicator of the degree of urbanization, distinguishing between Copenhagen, other towns (about 80), and rural areas. Currently, less aggregated information is not yet available. When estimating models, the $3 \%$ of individuals for whom birth location information is missing are assigned to the most common values (rural Jutland), except when we specifically focus on interaction effects of birth location.

\section{$2.2 \quad$ Business-cycle data}

As mentioned in the introduction, we use the business cycle as an exogenous indicator of early-life conditions. To appreciate the methodology, consider first the national annual per-capita gross domestic product (GDP) in constant prices. One could compare an individual born in an era with high GDP to an otherwise identical individual born in an era with low GDP. However, a prolonged era with a high GDP leads to innovation and investment in hygiene and health care, which decreases mortality later in life for those born in this era. These are secular improvements in life conditions over time, and they make this approach uninformative on effects of individual early life conditions. A related practical complication is that GDP displays a strong positive trend over time. A high GDP level at birth implies a high GDP level throughout life. An empirical analysis that tries to take this into account by allowing a mortality rate at a given age to depend on current and past GDP levels leads to estimates that are potentially very sensitive to small model misspecifications. For example, if the postulated relation is log-linear in the mortality rate and current GDP, and the true relation is slightly different, then this may show up as a significant effect of GDP earlier in life.

The effects of short-term cyclical movements in GDP are not affected by

descriptions of demographic developments in Denmark in our observation window, including aggregate cause-of-death information. 
Table 1: Summary statistics of the twin sample

\begin{tabular}{lrrr}
\hline \hline variable & \# cases & mean & st.dev. \\
& & & \\
(i) lifetime spells & & & \\
& 5749 & $95 \%$ & \\
uncensored & & 77.1 & 11.2 \\
among these: realized duration in years & 5671 & $99 \%$ & \\
among these: death cause observed & 25 & $0.4 \%$ & \\
right-censored at Jan 1, 1943 & 23 & $0.4 \%$ & \\
right-censored between 1943 and 2004 & 253 & $4 \%$ & \\
right-censored because still alive & & & \\
\end{tabular}

(ii) observed cause of death

\begin{tabular}{ll} 
cardiovascular & $53 \%$ \\
cancer & $21 \%$ \\
other & $26 \%$ \\
\hline
\end{tabular}

(iii) explanatory variables

male (vs. female) $\quad 49 \%$

monozygotic (vs. dizygotic same-sex) $37 \%$

birth region and urbanization (observed for 97\%):

Copenhagen $14 \%$

region Zealand excl. CPH $25 \%$

region Funen $\quad 12 \%$

region Jutland $\quad 50 \%$

urbanization: town excl. CPH $16 \%$

urbanization: rural $\quad 70 \%$

birth season:

Jan-Mar $27 \%$

Apr-Jun $24 \%$

Jul-Sep $\quad 24 \%$

Oct-Dec $24 \%$ 
secular improvements. Still, due to the gradual secular improvements over time, being born in a later stage of the cycle entails that the individual leads his life under somewhat better current conditions at each age. As a conservative strategy one may compare a cohort born in a boom to the cohort born in the subsequent recession, because the latter benefit more from secular developments than the former, so that an observed increase of a mortality rate can be attributed to the cyclical effect. More in general, one may relate a mortality rate later in life to the state of the business cycle early in life for many different birth years.

The raw GDP data are from Mitchell (2003). We deflate this nominal time series using the price index series of Johansen (1985) and Mitchell (2003). ${ }^{8}$ Next, we perform a trend/cycle decomposition of log annual real per-capita GDP using the Hodrick-Prescott (HP) filter. We use smoothing parameter 100 which is low but ensures that the time series of the cyclical component (or deviation) of GDP does not display a trend over the interval of birth years that we consider. Recall that if the cyclical component has a positive trend in the birth year interval then the estimation routine may incorrectly interpret this as evidence that the cyclical component at birth has a positive long run effect on longevity. In fact, the values of the cyclical terms are robust with respect to the actual decomposition method and smoothing parameter, and so are the resulting intervals within which the terms are positive or negative. In sum, good and bad transitory macro-economic conditions are clearly identifiable in the data.

Figure 1 displays the cycle and trend as functions of calendar time. We have 17 years with a positive cyclical component and 17 with a negative. On average, the number of consecutive years in which this component does not change sign equals 2. Among years with a positive (negative) component, this number is 1.9 (2.1).

\section{Some direct data evidence}

\subsection{The business cycle at birth, longevity, and CV mor- tality}

It is useful to start listing some sample features that should be kept in mind in the statistical analysis of sample descriptives. First, within-twin pair outcomes are related due to shared determinants. We cannot use within-pair outcome

\footnotetext{
${ }^{8}$ All time series used in this paper, including descriptions of their origin and/or construction, are available upon request.
} 


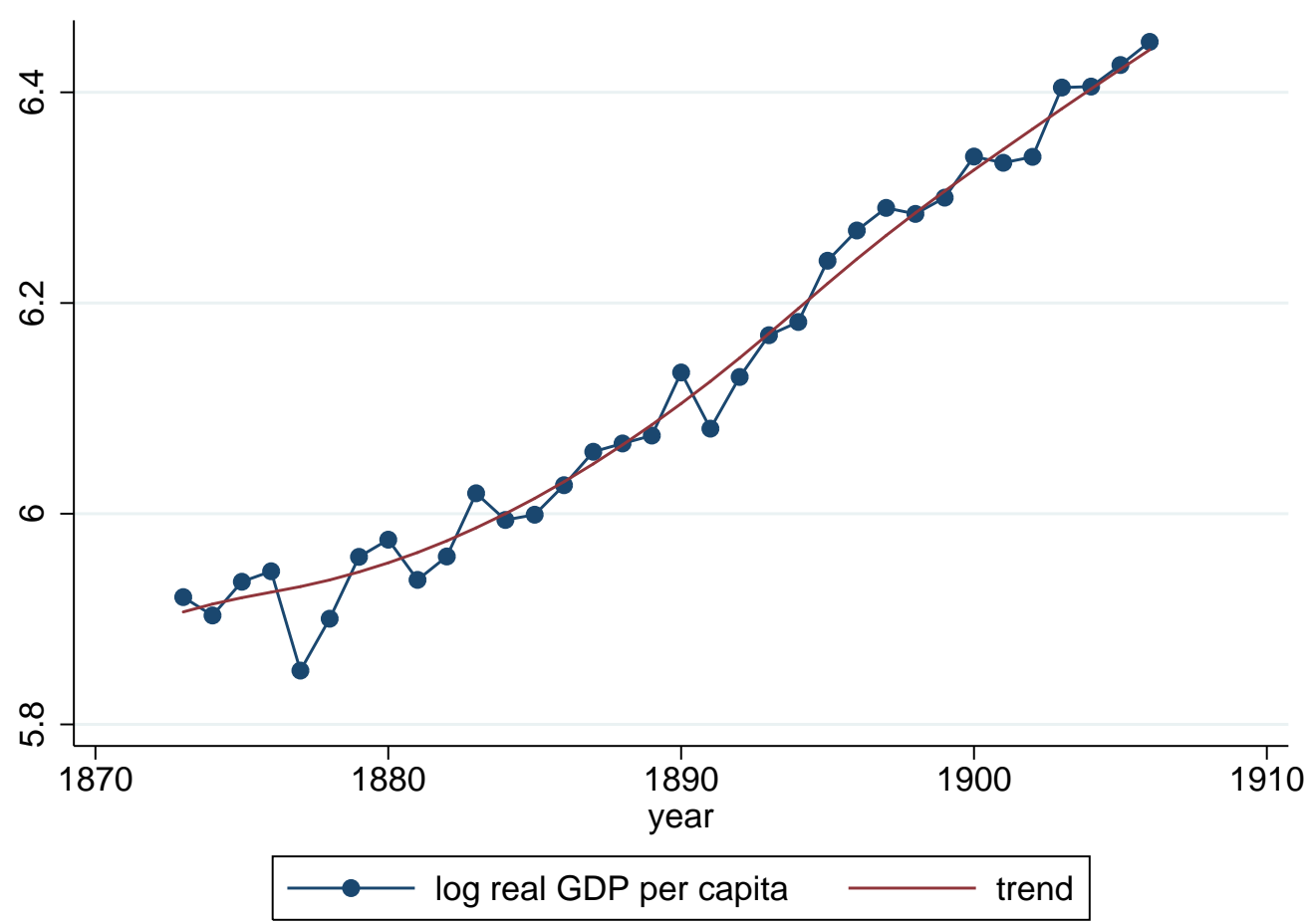

Figure 1. log real GDP per capita: trend and cycle

differences to study long-run effects of macro conditions, because the latter conditions are identical for both twins. (This does not mean that we cannot exploit the twin aspect to learn about the relative importance of shared and individualspecific determinants and their interactions; see Section 4.) Moreover, due to shared or related determinants, the sample of individual twins is not a sample of independent draws from the distribution of individual lifetimes of twins. This is exacerbated by the requirement that both twins be alive in 1943. Randomly discarding one individual per observed twin pair would complicate the selectivity in the sample of individuals, because survival of the co-twin until 1943 depends on the twin-specific frailty and on early-life conditions and on their interactions.

With this in mind, consider first the mortality due to all death causes. Due to the left-truncation of lifetimes in 1943, we cannot simply compare the observed average lifetime durations across different birth cohorts, even if we would aggregate booms and recessions and even though the cyclical indicator is orthogonal to any trends. This is because the left-truncation point varies across birth years. To proceed, we examine the mean lifetime duration $\mathbb{E}\left(T \mid T \geq 70, \tau_{0}\right)$ conditional on the age $T$ exceeding 70 , among those born in birth year $\tau_{0}$. We estimate this as the mean lifetime among uncensored lifetimes among those born in $\tau_{0}$ who 


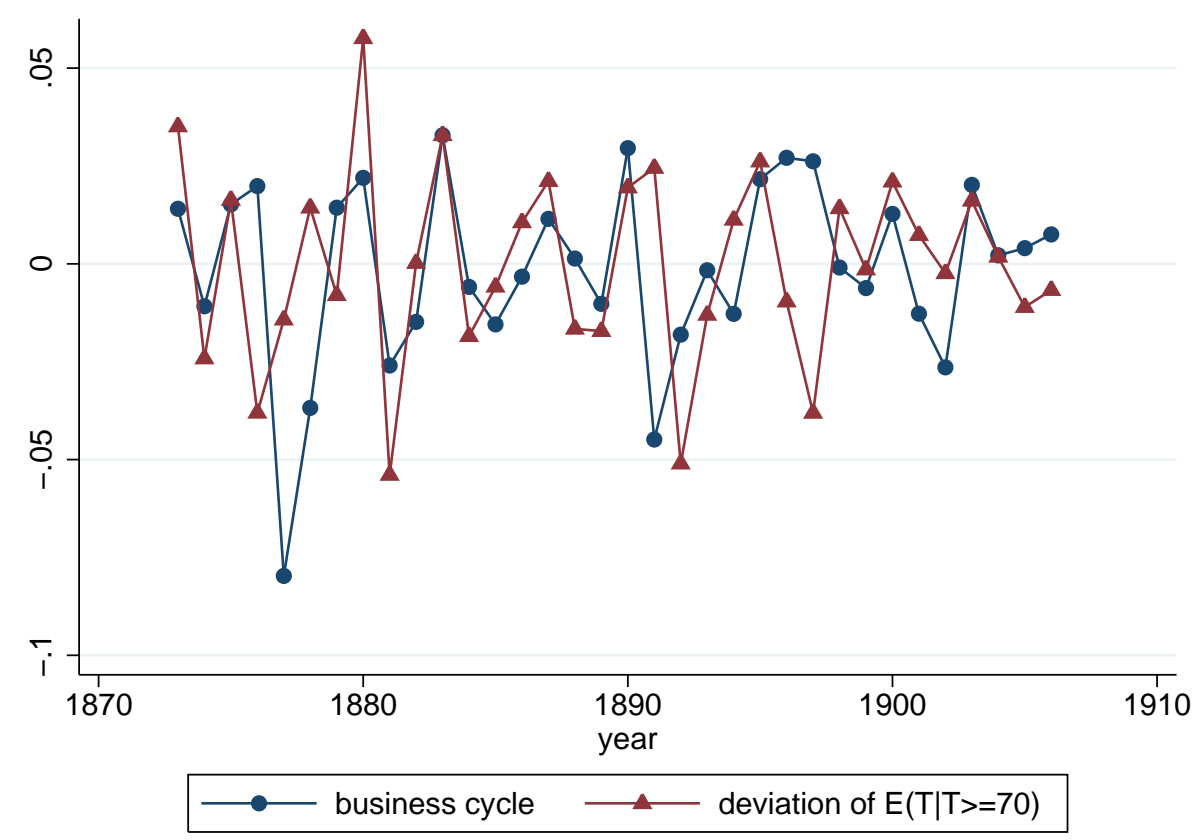

Figure 2. The business cycle and the transitory component in the mean lifetime in the birth cohort (conditional on survival until age 70).

survive until age 70, for each birth year. Subsequently, we obtain the deviation in the time series of $\mathbb{E}\left(T \mid T \geq 70, \tau_{0}\right)$ in order to remove the trend in longevity, and we correlate this deviation variable with the business cycle indicator at $\tau_{0}$. Figure 2 displays the two time series.

To interpret the displayed values, recall that the GDP cycle represents the percent deviation of annual real per-capita GDP from its trend value. The deviation of the mean conditional lifetime is measured in $10^{4}$ days, so that a deviation of 0.018 corresponds to 6 months.

The figure suggests a positive association, and indeed the estimated correlation between the two time series equals 0.3 . This provides some evidence that the business cycle at birth has a negative effect on the mortality rate at higher ages. Of course, this result does not exploit information in the individuals who do not reach the age of 70 or information in higher moments of the distribution of $T$. It is not straightforward to carry out formal statistical tests, due to the complex sampling variation in the twin data set. We may compare the mean lifetime among those born in years in which the business cycle component is positive, and compare this to the mean among those born in the other years, conditioning on $T \geq 70$ years. The observed difference is equal to 6.5 months in favor of those born in years with a positive business cycle component. Under the (incorrect) 
assumption of independence of within-twin pair lifetimes, we can calculate the standard error of the estimated difference, and we find that this difference is significant at the $1 \%$ level. If we only use at most one individual per twin pair in the data then the difference is still significant, at the $5 \%$ level. Equivalently, a one-sided test of equal versus shorter lifetimes for those born under adverse conditions would reject the null hypothesis of no difference at the $2.5 \%$ level. $^{9}$

To examine the dependence of within-pair lifetimes, we restrict attention to all 1677 pairs for whom both twins survive until age 70. The correlation between the lifetimes equals 0.20 and is significant at the $1 \%$ level. When considering only birth years in which the business cycle component is positive the correlation is 0.23 , whereas for adverse birth years the correlation is 0.19 . The difference is not significant (its standard error being 0.048), but the result is a first indication that genetic and shared environmental characteristics may be more important determinants of mortality later in life if early-life conditions are poor.

The above approaches that consider moments of lifetimes can not be used for CV mortality, because the duration until death due to CVD is often right-censored by death due to other causes. However, by assuming that all other death types constitute independent right-censoring of the duration until CV mortality, we can non-parametrically estimate the $\mathrm{CV}$ mortality rate, distinguishing by whether the business cycle component in the birth year is positive or not. Specifically, we use the Ramlau-Hansen kernel estimator for hazard rates (see e.g. Andersen et al., 1993). Figure 3 displays the estimates based on a kernel bandwidth of 3 years. Clearly, at most ages, the CV mortality rate is higher if born in an adverse birth year. (To gauge the figure, it is useful to point out that according to the KaplanMeier estimate of the all-cause survivor function, the median lifetime duration conditional on survival until age 36 is equal to 77.7 years, and the 25 th and 75 th percentile are 68.9 and 85.0.) This is confirmed by a comparison of the KaplanMeier estimates of the CV-specific survivor functions distinguishing by whether the business cycle component in the birth year is positive or not. The estimated median of the duration until CV mortality, conditional on survival until age 36, equals 83.9 years if one is born in a "bad" year, and 85.6 years if one is born in

\footnotetext{
${ }^{9}$ We can also apply this procedure without the restriction that $T \geq 70$. This amounts to a comparison of the means of mixtures of distributions with lower truncation points ranging from 36 to 70 years. If the business cycle effect is monotone across ages then the difference may be informative on the long-run effect that we are interested in. The observed difference again equals 6.5 months in favor of those born in years with a positive business cycle component. Under the assumption of independence of within-twin pair lifetimes, this is significant at the $10 \%$ level.
} 


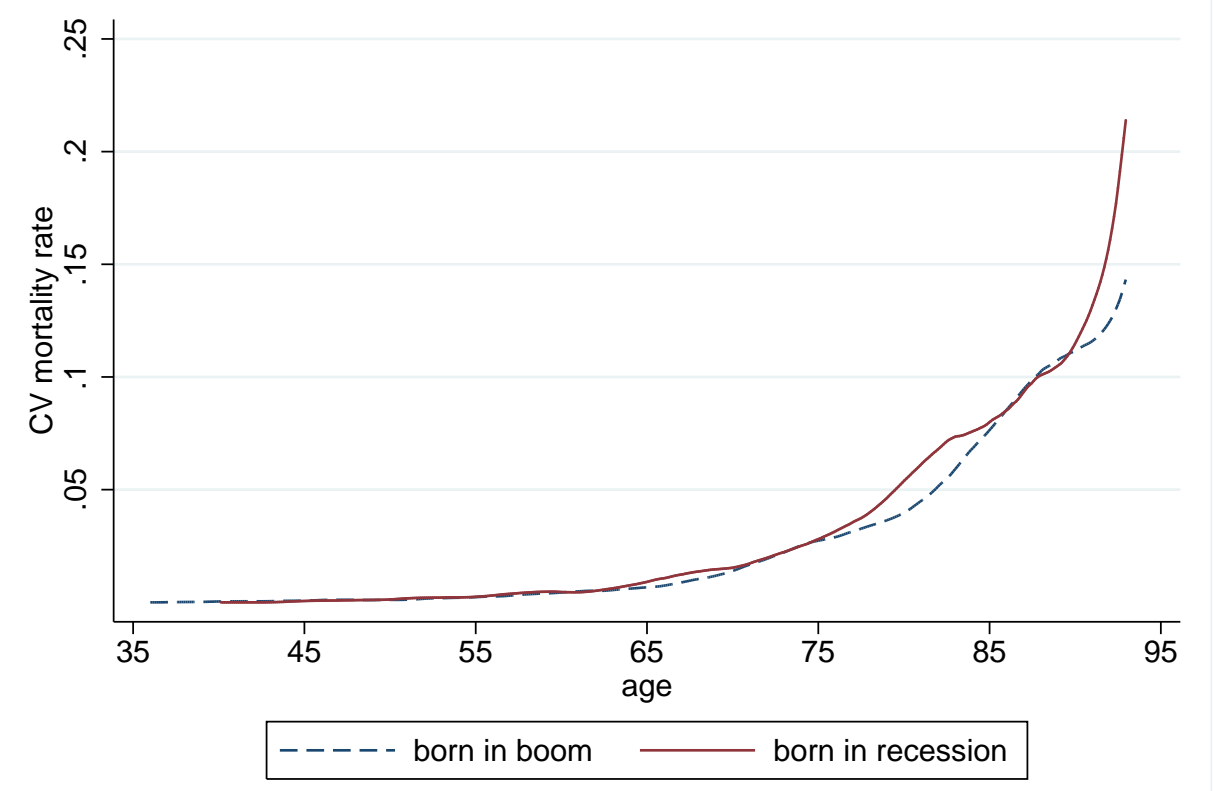

Figure 3. Non-parametric estimates of the $C V$ mortality rate by whether the cycle at birth is $\gtrless 0$.

a "good" year. ${ }^{10}$

It is also interesting to examine how the fraction of deaths due to CVD depends on the business cycle in the birth year, although this also depends on how mortality due to other death causes varies with the cycle. It turns out that the estimated fraction due to CVD equals 0.522 if one is born in a "good" year and 0.536 if one is born in a "bad" year. This is in agreement with the hypothesis that the CV mortality rate later in life is higher if one is born under adverse conditions. However, under the assumption of independence of within-twin pair lifetimes, the estimated difference is not significant.

The signs of the estimated effects in this section unambiguously support the hypothesis that adverse early-life conditions increase (CV) mortality later in life. In Subsections 4.2-4.4 we present model estimation results.

\footnotetext{
${ }^{10}$ Like above, formal tests are not straightforward. Moreover, any non-parametric test would vulnerable to systematic heterogeneity in the $\mathrm{CV}$ mortality rate and in the censoring due to other death causes.
} 


\section{Estimation of duration models for the indi- vidual $\mathrm{CV}$ mortality rate}

\subsection{Models for individual mortality rates}

\subsubsection{Basic model specification}

The individual (CV) mortality rate is the natural starting point of the specification of the model, because of our interest in its dependence on conditions early in life. As our model specifications closely follow those in the literature, the present exposition can be brief. Age is measured in days, so we take it to be a continuous random variable. Let $\tau$ denote current calendar time. We may express the (CV) mortality rate $\theta$ of an individual at a given point of time in terms of the prevailing age $t$, individual background characteristics $x$, current conditions $z(\tau)$, exogenous business-cycle indicators $c(\tau-t)$ of early-life conditions, unobserved characteristics or frailty $V$, and various interaction terms. For example,

$$
\log \theta(t \mid x, z, c(\tau-t), V)=\psi(t)+\beta_{1}^{\prime} x+\eta^{\prime} c(\tau-t)+\beta_{2}^{\prime} z(\tau)+\log V
$$

where $\eta$ is the parameter of interest. This is a Mixed Proportional Hazards model with time-varying regressors $z$. This can be straightforwardly extended to allow for effects of conditions early in life after birth (say, $c(\tau-t+a)$ for given $a>0)$ or conditions in utero (say, $c(\tau-t-a)$ with $a$ between 0 and 9 months).

Throughout this section, we capture long-run secular and current trend effects $z(\tau)$ by way of a low-order polynomial in the log birth year. We could as well take a low-order polynomial in $\tau$. A seemingly more general specification with polynomials in $t, \tau-t$ and $\tau$ would be susceptible to the so-called age-periodcohort identification problem. In fact, we mostly take a log-linear function in $\tau-t$. Note that we can thus subsume $z$ into $x$ and $\beta_{2}$ into $\beta_{1}$ (or, in shorthand, $\beta)$.

In the absence of unobserved heterogeneity, the model reduces to a PH model, and the parameters $\beta$ and $\eta$ can be estimated with Partial Likelihood Estimation. This means that the age-dependence function $\psi$ (or "force of mortality" or "baseline hazard") is left unspecified when estimating these parameters. In the above framework, absence of unobserved heterogeneity implies independence of the within-twin pair lifetimes conditional on the covariates $x$, the (shared) earlylife conditions, and the secular effects as captured by the birth year. The Partial Likelihood approach thus tackles at least part of the unconditional dependence of 
within-pair lifetimes, which was a complicating factor in the descriptive analyses of the previous section.

\subsubsection{Implications of ignored heterogeneity among newborns and ev- idence on the lack of compositional changes}

Unobserved heterogeneity among newborns that is not taken into account in the estimation can bias the estimates of long-run effects of early-life conditions. We distinguish between within-cohort heterogeneity on the one hand, and systematic between-cohort variability in the composition of newborns on the other.

To address the effect due to within-cohort heterogeneity, notice that covariate effects on the hazard rate are typically biased towards zero if unobserved heterogeneity is ignored (see Van den Berg, 2001, for an overview of the literature). Recall that we only observe lifetime durations if they exceed the twins' ages in 1943. With unobserved heterogeneity, dynamic selection may lead to an overrepresentation of high-age survivors with favorable characteristics, among those born in adverse years (see e.g. Vaupel and Yashin, 1985, for details). So if unobserved heterogeneity is present but is not taken into account then the coefficient $\eta$ of the indicator of early-life effects can be expected to be biased towards zero, and the true effect is likely to be at least as large in absolute value. This also applies to the effects of a possible increase in stillbirths and spontaneous abortions during adverse conditions.

This problem may be less relevant than in other studies of effects of early-life conditions on mortality much later in life. Among all countries and all eras up to the 20th century, Denmark had the lowest infant mortality ever. Alternative indicators of early-life conditions focusing on extreme events like epidemics or famines may lead to peaked infant mortality and strong ensuing dynamic selection of the fittest in the cohort.

Another implication of within-cohort variability is that most likely it leads to statistical dependence of twins' lifetimes. After all, both of these will be affected by shared characteristics that are not among the observed covariates $x$. Failure to take this dependence into account may lead to under-estimation of coefficient standard errors. This is particularly relevant in our setting because of the requirement that both twins are alive in 1943, which has a different statistical meaning if the twins are born in 1906 than if they are born in 1873. We also have a more substantive reason to incorporate unobserved heterogeneity, because we want to inquire whether environmental features and genetic determinants have a stronger impact if one is born under adverse conditions, and most of these features and determinants are unobserved. We therefore also estimate models allowing 
for unobserved heterogeneity in personal and environmental characteristics (see Subsection 4.1.3).

We now turn to between-cohort variation in the distribution of unobservable personal characteristics. It is conceivable that the distribution of CV-mortality determinants among newborns varies over the cycle. A long-run association between the business cycle at birth and high-age mortality can be explained if parents with adverse unobserved permanent characteristics (like a low social class) more often have offspring during recessions. We investigate this in two ways. First we examine fluctuations in cohort sizes, following the idea that systematic variation in cohort size leads one to suspect systematic changes in the composition. (For example, Saugstad, 1999, shows that in Denmark, changes in the composition of newborns go along with changes in birth rates.) Secondly, we discuss direct evidence on the composition. This includes an examination of the fraction of twins itself among newborns.

It turns out that the yearly deviation in the national Danish birth rate is not significantly related to the business cycle indicator in our birth-year window or in larger windows. The same applies to the national rate of twin births (i.e. \# twin births / population size). Fluctuations in the latter rate are primarily driven by fluctuations in the national twinning rate (i.e. \# twin births / \# births) and not by fluctuations in the birth rate. Interestingly, the yearly deviation in the twinning rate is significantly positively related to the business cycle indicator over the birth years 1873-1906. The correlation equals 0.35 (standard error 0.16). ${ }^{11}$ However, the corresponding regression coefficient is very small. Over the period 1860-1944, the correlation equals 0.14 and is not significant. The full Twin Registry can be used to obtain a separate estimate of the twinning rate. For this, we divide the number of twin pairs of whom both members reach the age of six (including those with unknown zygosity) by the number of births in the birth year. It turns out that yearly deviations in this measure are similar to those in the national twinning rate (e.g. over the period 1870-1910 the correlation is 0.69 ), and accordingly it is also significantly positively related to the business cycle indicator over 1873-1906, with a correlation of 0.37 (standard error 0.17). There are no significant relations to the cycle in the year before birth.

\footnotetext{
${ }^{11}$ In the literature, regional and temporal variations in natural DZ twinning rates are explained by the mean maternal age and parity, by the degree of genetic heterogeneity in the relevant population, and by psychosocial pressures in society (stress). See Eriksson and Fellman (2004) for an overview and for historical results for Sweden. Bortolus et al. (1999) provide a meta-study of articles in which twinning is examined at the individual level. They confirm that maternal age and genetic heterogeneity are important, and they conclude that social class is not a major determinant.
} 
Official stillbirth rates in Denmark at the end of the nineteenth century were low and fairly constant over time. Statistics Denmark, 1902, gives data for 18901901. The average is about $2.5 \%$. The yearly rate is not significantly related to the business cycle. ${ }^{12}$

We conclude from all this that fertility is independent of the contemporaneous state of the business cycle, whereas the fraction of twin births is slightly higher in booms. The latter suggests that twins are relatively frail and therefore that the twins born in recessions constitute a somewhat advantageous selection from the population of potential (conceived) twin pairs of which at least one individual survives until after birth. This is in line with stress having an adverse effect on twinning rates (Eriksson and Fellman, 2004). By analogy to the discussion of within-cohort heterogeneity, this again may cause the indicator of early-life effects to be biased towards zero, implying again that if we find an effect then the true effect may be larger.

To shed some more light on changes in the composition of newborn twins over the business cycle, we use data from a survey held in 1966 among same-sex twins in the Twin Registry born in 1890-1920 with known zygosity. These data were used by e.g. Herskind et al. (1996) and include the level of education and the social class in 1966. Social class is derived from the occupational hierarchy and is closely associated to income. The intersection of the cohorts in the survey data and our birth-year observation window (i.e. 1890-1906) contains 1480 individuals. We find that there is no significant relation between the level of education and the business cycle in the birth year. The same applies to social class. If anything, the fraction with low social class is slightly higher among those born in booms. Of course, the education and social class variables are potentially endogenous since they may be affected by early-life conditions. Moreover, the survey data only includes survivors until 1966. Among those born in 1890, only $50 \%$ survive until then, whereas among those born in 1906, 90\% survive. However, the results are the same if we compare two adjacent years where one is a boom year and the other a recession year (like 1902 and 1903). The results are not due to socialclass differences in infertility; Schmidt, Christensen and Holstein (2005) provide population-based evidence that in Denmark, infertility is unrelated to social class.

Other studies with data from Northwest Europe from around 1900 also fail to find that the social-class composition of newborns is systematically related to fluctuations in macro indicators early-life conditions. Van den Berg, Lindeboom and López (2006) examine how the size and the composition by social class of a

\footnotetext{
${ }^{12}$ In Sweden around 1900, the stillbirth rate among twins equals around $8 \%$ while the rate for singletons was as in Denmark; see Fellman and Eriksson (2006).
} 
birth year cohort changes with the cyclical indicator of the business cycle at birth. Their data are from the Netherlands and contain the social class of the parents at the moment of birth. They conclude that there are no such effects. Kåreholt (2001) studies Swedish birth cohorts from 1897-1938 and examines whether the fraction of newborns whose father had a blue (vs. white collar) occupation varies with the state of the business cycle as measured by the annual change in the inflow into poor relief. The results show that there is no significant difference among male and among female newborns.

Finally, we use our data to examine the composition of newborns by urbanization degree and region. It turns out that the regional composition among newborn twins does not fluctuate over the business cycle, but that in recessions slightly more twin births are observed in rural areas as opposed to towns. Note however that we condition on these variables in the empirical analyses.

The above evidence suggests that the composition of newborn twins in terms of social class, education, and other personal characteristics does not vary systematically over the business cycle.

\subsubsection{Correlated Frailty Model}

To incorporate unobserved heterogeneity, we adopt the Correlated Gamma-Frailty Model which is often used in demography to study twins' lifetimes (see e.g. Wienke et al., 2001, 2002). This model postulates that the within-twin pair frailty terms follow a Cherian bivariate Gamma distribution. It allows for an interpretation of the individual frailty term as the sum of an individual-specific term and a shared twin-specific term. The shared term $W$ captures shared genetic determinants and relevant features of the shared environment in which the twins lived. The individual-specific term $V^{0}$ captures individual-specific characteristics that are not shared with the co-twin. In the context of our study, consider a twin pair with twins labelled by index $i=1,2$. For each twin, the individual log CV mortality rate equals, in obvious notation,

$$
\log \theta\left(t \mid x, c(\tau-t), V_{i}\right)=\psi(t)+\beta^{\prime} x+\eta^{\prime} c(\tau-t)+\log V_{i} \quad \text { with } i=1,2
$$

where, for twin $i$, we can write

$$
V_{i}=V_{i}^{0}+W
$$

where $V_{1}^{0}, V_{2}^{0}$ and $W$ are independent (and independent of $x$ and the moment of 
birth), and all terms in (2) are Gamma distributed. ${ }^{13}$

In particular, the joint distribution of $V_{1}, V_{2}$ follows a bivariate Gamma distribution. Of course, the marginal distributions should be identical. We may normalize their mean to one by subsuming it into the constant term of $\beta^{\prime} x$. As a result, the joint distribution of $V_{1}, V_{2}$ has two parameters: the variance $\sigma^{2}$ of $V_{i}$ and the correlation $\rho$ of $V_{1}$ and $V_{2}$. The latter equals the fraction of the total variance of $V$ explained by $W$,

$$
\operatorname{corr}\left(V_{1}, V_{2}\right)=\rho=\frac{\operatorname{var}(W)}{\operatorname{var}\left(V_{i}\right)}
$$

Note that $\rho \geq 0$ but this is hardly restrictive in our study.

Subsequently, we may allow $\rho$ to depend on the zygosity of the twin pair (as in e.g. Wienke et al., 2002), and we may also allow it to depend on the business-cycle indicator of early-life conditions (see Subsection 4.2 below for the interpretation of this).

For our purposes we need to parameterize the age-dependence function $\psi$ in the Correlated Gamma-Frailty Model. We assume that this is a Gompertz function, i.e. $\psi(t)=\alpha t$. With lifetime durations of older individuals, this functional form is not controversial and is known to give an acceptable fit to age dependence in many cases. $^{14}$

\footnotetext{
${ }^{13} \mathrm{~A}$ random variable $Y$ with density $\lambda^{k} y^{k-1} e^{-\lambda y} / \Gamma(k)$ is said to have a Gamma distribution with scale parameter $\lambda$ and shape parameter $k$. It satisfies $\mathrm{E}(Y)=k / \lambda$ and $\sigma_{Y}^{2}:=\operatorname{var}(Y)=$ $k / \lambda^{2}$, implying that if $\mathrm{E}(Y)=1$ then $\lambda=1 / \sigma_{Y}^{2}$.

Now consider three independent random variables $V_{1}^{0}, V_{2}^{0}$ and $W$, where $V_{1}^{0}$ and $V_{2}^{0}$ have a Gamma distribution with scale parameter $\lambda$ and shape parameter $k_{0}$, and $W$ has a Gamma distribution with scale parameter $\lambda$ and shape parameter $k_{\omega}$. It can be shown that $V_{i}:=V_{i}^{0}+W$ then has a Gamma distribution with scale and shape parameters $\lambda$ and $k_{0}+k_{\omega}$, respectively, for each $i=1,2$. If we normalize the mean of $V_{i}$ to equal one, so that $\lambda=k_{0}+k_{\omega}$, then it follows that $\operatorname{var}\left(V_{i}\right)=1 /\left(k_{0}+k_{\omega}\right)$ and $\operatorname{corr}\left(V_{1}, V_{2}\right)=k_{\omega} /\left(k_{0}+k_{\omega}\right)$. These can then be redefined as parameters $\sigma^{2}$ and $\rho$.

${ }^{14}$ In single-spell duration analysis with MPH models and samples of independent outcomes, parameter estimates are known to be sensitive to functional-form assumptions on $\psi$ and the distribution of $V$ (see Van den Berg, 2001, for an extensive overview of the evidence). In our setting, this is less likely to be an issue. First, the correlation between the observed within-twin pair outcomes is directly informative on the correlation $\rho$ between the unobserved determinants, as the latter is the only source of correlation of the former. Secondly, the presence of a withintwin pair correlation between the frailty terms implies that multiple observations drawn from the same marginal distribution are affected by related unobserved frailty terms. Identification results for multiple-spell duration models suggest that estimation results are less driven by functional-form or multiplicity assumptions than if the data are from an i.i.d. sample of spells. Thirdly, recall that the Gompertz functional form for $\psi$ is relatively well-grounded. In any case, even in misspecified MPH models, the sign and significance of the covariate effects are usually
} 
Note that cause-specific mortality is right-censored by mortality due to other causes. One may question the assumption that such censoring is non-informative on the CV mortality rate conditional on the observed covariates. Wienke et al. (2002) extend the above Correlated Frailty Model by allowing unobserved determinants of different cause-specific mortality rates to be stochastically dependent. They estimate models with Danish twin data distinguishing between mortality due to coronary heart disease and mortality due to all other causes. They do not find a significant dependence between the unobserved determinants of the two cause-specific mortality rates. We take this as support for our assumption of non-informative censoring of CV mortality.

We estimate the Correlated Frailty Models by Maximum Likelihood, using the GAUSS program, taking account of the left-truncation of both twins' lifetimes at the age reached in 1943 and taking account of right-censoring due to missing information on the death date and right-censoring due to death being caused by another cause (see Wienke et al., 2002, for expressions of the full likelihood function).

\subsection{Estimation results}

Table 2 gives the partial likelihood estimates of the most basic Cox $\mathrm{PH}$ model specifications. The estimates concern the CV mortality rate, so a positive value is associated with a shorter CV lifetime. One specification has a more parsimonious set of covariates than the other. In both specifications, being born in a recession increases the CV mortality rate by $12 \%$. The estimate is strongly significant. This is the first main result of the paper, and as we shall see it is robust to many departures from the basic model specifications. The result implies a significant causal effect of economic early-life conditions on CV mortality much later in life, and as such it bridges the gap between the economic and medical literatures.

The implied causal effect of the business cycle at birth on the mean lifetime conditional on $T \geq 40$ is as follows. If an individual is born in a boom as opposed to a recession, then one can expect to live 0.8 years longer beyond age 40 , just because the risk of $\mathrm{CV}$ mortality is lower. In both specifications we use the binary "recession" indicator because large observed deviations from the GDP path may contain measurement errors. In Subsection 4.3 we show that the results are also correctly inferred (see again Van den Berg, 2001). We therefore expect that the inference on the sign and significance of the causal covariate effects (including the effect of the business cycle early in life), and the inference on the correlation between the frailty terms, are robust with respect to functional-form assumptions. Wienke et al. (2005) confirm this in a simulation study of misspecified Correlated Frailty Models. 
robust with respect to the measure used.

The other covariate effects are as expected. The log-linear birth year effect is negative, confirming that CVD became a less dominant cause of mortality in our observation period. The effects of birth season are in accordance to those reported in Doblhammer (2004) based on a larger set of Danish twins. A Likelihood Ratio (LR) test confirms joint significance of seasonal effects (p-value equals 0.002). Individuals born in Copenhagen have a higher CV mortality rate, but apart from this, the CV mortality rate does not vary over the country or between towns and rural areas. An LR test leads to acceptance of the null hypothesis of no birth location effects (p-value equals 0.16). ${ }^{15}$ The CV mortality rate is not significantly different between MZ and DZ twins. This is a common finding if one restricts attention to twins surviving infancy (see e.g. Christensen et al., 1995, and Wienke et al., 2001). Differential infant mortality rates may give rise to a dynamic selection process in which the health composition of the MZ twins improves with age such that it becomes similar to that of the DZ twins. An alternative explanation is that $\mathrm{MZ}$ twins communicate more often with each other concerning health issues and that the ensuing increase in health knowledge leads to a reduction of their mortality rate (see Zaretsky, 2003, for empirical evidence on this).

According to an LR test, the parsimonious specification does not give a worse fit than the extended specification (p-value 0.19). We have two reasons for working with the parsimonious set of covariates. First, Maximum Likelihood estimation of Correlated Frailty Models becomes cumbersome if the number of covariates is large, in particular if we allow the parameter $\rho$ to depend on $x$ and the value of $\rho$ is close to (or equals) 1 or 0 for some values of $x$. Secondly, we want to assess the sensitivity of the results with respect to a wide range of model assumptions, and these results are more easily discussed for a parsimonious specification. In the latter specification, we only consider a birth season effect for those born in the spring, as the spring is most often identified as the main disadvantageous birth season in the literature (Doblhammer, 2004). In addition, we only consider a birth location effect for those born in Copenhagen, because the results so far suggest that this effect is an order of magnitude larger than the effects for other locations.

Before we turn to estimation of Correlated Frailty Models, we consider the dependence of the CV mortality rate on age (the "force of CV mortality"). In

\footnotetext{
${ }^{15}$ In Subsection 4.4 we examine interaction effects of the business cycle at birth and the degree of urbanization. Interacting the former with sex results in a somewhat larger "recession" coefficient for men.
} 
Table 3 we estimate the parsimonious model with the restriction that the age dependence function $\psi$ is a Gompertz function, i.e. $\psi(t)=\alpha t$. We estimate the model using Maximum Likelihood. Clearly, the covariate effects are the same as in Table 2. This suggests that the Gompertz specification for the CV mortality rate is accurate for higher ages; note that is in accordance to Figure 3. The same conclusion follows with the extended set of covariates.

Table 4 displays the Maximum Likelihood estimates of Correlated GammaFrailty Models with a Gompertz age dependence and with the parsimonious set of covariates. The covariate effects (notably, the "recession at birth" coefficient) are similar in sign and relative magnitude and in significance as in the Cox $\mathrm{PH}$ specification in Table 2. The individual effects and the age dependence are mostly somewhat larger in absolute value, and this is exactly what one expects if unobserved heterogeneity is incorporated in the model. Similarly, the standard errors are somewhat larger, and this is to be expected if inter-individual outcome dependence is incorporated.

We now turn to the estimated correlation coefficients of the bivariate frailty distribution. First, note that the coefficient for MZ twins always exceeds the coefficient for DZ twins. This is to be expected, as MZ twins are genetically identical whereas DZ twins are not, while the average influence of the environment can be expected to be more or less the same for both types. In fact, the estimated correlation for MZ twins is at the upper boundary (i.e., at 1) of the parameter space. This is not inconsistent with a true parameter value smaller than 1 , but it is not possible to test this since there is no standard error associated with an estimate at the boundary. Note that even if the true value of $\rho$ equals 1 , this does not mean that the correlation between the lifetimes (whether conditional on $x$ and $V$ or not) is 1 .

The estimated correlation $\rho$ for DZ twins equals 0.85 if born in a recession (with standard error 0.17 ), and 0.49 if born in a boom (with standard error 0.0085). The fact that the former standard error is much larger than the latter merely reflects the fact that the likelihood function is very flat in $\rho$ for values of $\rho$ close to one. We reject the null hypothesis that states that within-pair lifetimes for DZ twins do not depend on early-life conditions. The difference between the estimated correlations equals 0.36 , and this is significantly different from zero at the $5 \%$ level, as the standard error of the difference (estimated with the Multivariate Delta method) equals 0.17 (so the t-value is 2.2). Alternatively, we may use an LR test. Estimation of the restricted model in which the correlation for DZ twins does not depend on the cycle at birth results in a point estimate of 
0.65 for this correlation. ${ }^{16}$ The LR test statistic equals 2.8 , which is significant at the $10 \%$ level. We now turn to the interpretation of the estimated correlation coefficients.

Correlated Gamma-Frailty models that are estimated with twin data can be used to decompose variation in the outcome into components reflecting genetic, environmental, and individual-specific terms (see e.g. Wienke et al., 2002, for a detailed exposition). For a given zygosity, the non-shared variation in the frailty term captures variation due to unobserved individual-specific determinants, whereas the shared variation captures variation in unobserved shared genetic determinants and variation in the unobserved shared environmental determinants, such as conditions of the household in which the twins grow up. Typically, the results of this decomposition are subsequently compared by zygosity, but we may also make a comparison across twin pairs with different early-life conditions.

Our estimates for MZ twins are not very informative in this respect, since they are at the boundary of the parameter space. These point estimates imply that, among MZ twins, all variation in the systematic determinants of the $\mathrm{CV}$ mortality rate is shared, but as we have seen, the boundary estimates may be a small-sample result. They may also be affected by functional-form assumptions like the assumed proportionality of $\theta$ in terms of $V_{i}$. In any case, the similarity of within-MZ pair outcomes precludes application of the above decomposition. The estimates for DZ twins are more informative. They imply that shared genetic and environmental factors are more important for $\mathrm{CV}$ mortality if the individual is born under adverse economic conditions. Individual-specific factors dominate stronger the individual in born under better conditions.

This is an interesting result. In short, individual-specific qualities come more to fruition if the starting position in life is better. Or, individuals with individual features protecting for CVD will not benefit so much from them if they are born under adverse economic conditions. If one interprets the business cycle itself as an environmental factor, then one may formulate the conclusion that nature and nurture interact in their effect on CV mortality.

\footnotetext{
${ }^{16}$ All other coefficients are virtually equal to those in Table 4 . In particular, the "recession at birth" coefficient equals 0.14 (t-value 2.8).
} 


\subsection{Sensitivity analyses and additional results}

\subsubsection{The effect of the timing of the birth in the year and the business cycle around the birth year}

The first column of Table 5 presents estimates of the PH model where the transitory component of log annual real per capita GDP is included as a covariate instead of the binary indicator. To compare the results to those in Table 2, note that a negative effect corresponds to a positive effect of the binary indicator, and that the transitory component ranges between -0.025 and 0.025 . The transitory component has a significant negative effect on the CV mortality rate, and the results are virtually the same as before, although the fit is marginally better for the binary indicator. In general, the results are very robust with respect to how cyclical conditions are measured. This includes changes in the smoothing parameter for the GDP decomposition.

Next, we investigate whether the CV mortality rate later in life also depends on the business cycle in the year before birth and in the years after birth. This may give some insight into whether economic early-life conditions are primarily of importance in utero or at birth or in the years after birth. A priori one may expect any of these three stages to matter, as outlined in the overview of Barker (2007). The second column of Table 5 presents estimates of a model where the business cycle indicator in the year before the birth year ${ }^{17}$ and the three years after the birth year are included as covariates. All corresponding coefficients are positive, which is in agreement to a long-run effect of adverse conditions in utero and in the years up to age 3. However, the coefficients are very small and are (jointly) completely insignificant. In particular, the coefficients are much smaller than for the business cycle indicator at birth. The coefficient of the latter indicator has virtually the same magnitude and standard error as before. This suggests that economic conditions during pregnancy and at age 1-3 are not important for CV mortality later in life, contrary to economic conditions at and shortly after birth.

We can study the effect of conditions during pregnancy more precisely by taking the date of birth within the birth year into account. We interact the season of birth with the business cycle in the year before birth. If the corresponding coefficient monotonically decreases from the winter season to the spring and summer season to a value of zero for the fall season, then this would suggest that the economic conditions while in utero, in particular during the last three months of pregnancy, are important. However, the results (Table 5, final columns) show

\footnotetext{
${ }^{17}$ For 1872 we impute the value zero for the indicator, because the transitory component is positive in that year.
} 
that all interaction coefficients are very small and are insignificantly different from zero. Of course, estimates of business cycle effects by birth season are effectively driven by rather small sample sizes (about $1 / 4$ of the full sample). Also, GDP is measured at a yearly frequency, and this makes it an imperfect measure of macro-economic conditions at the very beginning and/or end of the year. For these reasons, the findings in this paragraph should be taken with some caution.

\subsubsection{The over-all mortality rate and the cancer mortality rate}

We replicate the analysis of the CV mortality rate for two other mortality rates: the mortality rate for all causes, and the cancer mortality rate. The results are summarized in Table 6.

Clearly, the cycle at birth has a significant effect on the over-all individual mortality rate later in life. On average, being born in a recession implies a higher mortality rate later in life. Of course, this is to a substantial extent driven by the effect on the CV mortality rate, since CV mortality accounts for more than half of all mortality. The coefficient in the over-all mortality rate is slightly smaller than the coefficient in the $\mathrm{CV}$ mortality rate, but the effect on over-all lifetime durations is larger than if the long-run effect would only work through CV mortality. Specifically, the causal effect of the business cycle at birth on the mean lifetime conditional on $T \geq 40$ is such that being born in a boom as opposed to a recession results in 1.25 additional years. This result is remarkably similar in magnitude to the result in Van den Berg, Lindeboom and Portrait (2006) for the effect of the business cycle at birth on longevity in the Netherlands for the birth cohorts 1815-1902.

We may conclude that adverse economic conditions early in life lead to an increased over-all mortality rate much later in life. We now turn to the cancer mortality rate. Cancer was not such a major death cause as CVD, so the statistical analysis is relatively imprecise. Nevertheless, some interesting results appear. First of all, the business cycle at birth does not have a significant effect on the cancer mortality rate. The sign of the coefficient is positive, suggesting higher cancer incidence for those born under adverse conditions, but the magnitude is very small compared to the coefficient for the CV or the over-all mortality rate.

In fact, the medical evidence does not lead us to suspect that the over-all cancer mortality rate late in life is higher in case of adverse economic conditions around birth. Ben-Schlomo (2001) and McCormack et al. (2003, 2005) report positive associations between birth weight and the rates at which certain types of cancer occur at higher ages. By analogy to the negative association between birth weight and CVD, this actually suggests that improved economic conditions 
at birth might lead to a higher rate of certain cancers.

In Table 6 we find a positive time trend coefficient in the cancer mortality rate. Note also that the effect of being born in Copenhagen is larger for the cancer mortality rate than for the CV mortality rate.

\subsection{Underlying mechanisms}

The long-run effects of the business cycle at birth can be attributed to a range of aspects of individual early-life conditions, like inferior nutrition, and inferior housing conditions, with inadequate heating and crowdedness. Moreover, the stress level in the household may be higher in case of (a higher probability of) job loss. Adverse aggregate conditions may also cause a higher disease load exposure for infants at the individual level. We shed some light on this by interacting the business cycle at birth with regional indicators and the degree of urbanization. To interpret the results, we use historical studies of living conditions in Denmark in the nineteenth century, notably Løkke (2002), Johansen (2002a, 2002b), and Henriksen (2006), and references therein.

We start by interacting the recession indicator with the urbanization variable. For the full sample, it turns out that the recession effect does not vary with the degree of urbanization (i.e., it is virtually equal over towns, rural areas, and Copenhagen). The same applies to the recession effect by region. However, the historical literature suggests that urbanization may play a different role in different regions, due to differences in nutritional habits across regions (see in particular Løkke, 2002). We therefore proceed by estimating models on the subsample of those born on the island of Zealand (which includes Copenhagen). This region is relatively small and it displays the highest variation in the degree of urbanization. For this sub-sample of 2262 individuals, the coefficients of the basic model without interactions are very similar to those in Table 2. In particular, the recession at birth has a coefficient of $0.14(\mathrm{t}=2.4)$, while "Copenhagen" and "town" have coefficients of $0.15(\mathrm{t}=2.2)$ and $0.03(\mathrm{t}=0.3)$, respectively. As before, these additive urbanization coefficients can not be interpreted as long-run effects, because they also reflect instantaneous effects at higher ages.

Table 7 provides the estimates of the model for Zealand and Copenhagen with interactions between the recession and urbanization indicators (note that the sample size is about one third of that in the other tables). Clearly, recessions at birth have the strongest adverse effects in towns (coefficient 0.34, with t-value 2.1), whereas the effects in Copenhagen and in rural areas are in line with the national estimate. By implication, birth in a town during a recession leads to the 
same CV mortality rate later in life as birth in Copenhagen during a recession, whereas in a boom year it is much more advantageous to be born in a town. From the historical literature, a plausible explanation for the difference between the size of the interaction coefficients is that in Copenhagen the sanitary conditions and the health care system were superior to those in other towns. This includes the provision of clean milk to infants after breastfeeding, which was responsible for low infant mortality after the first months. In towns during recessions, the effects of inferior nutrition on the mother's and infant's health status could not be mitigated by good sanitary conditions or health care access. In rural areas, sanitary conditions were not as inadequate as in towns, while access to nutrition was easier than in towns. Notice that this explanation is in line with our finding that economic conditions right after birth are more important that those just before birth.

This suggests that the combination of nutritional quality and health infrastructure is important for long-run effects of early-life conditions, in the sense that if both are lacking then high-age CV mortality is affected. Along this line of reasoning, adverse economic conditions leading to suboptimal early-life nutritional patterns are more harmful in the long run if the health infrastructure early in life is inadequate. Of course, we also find long-run effects for those born in areas where both are not lacking. These may capture a separate long-run effect of nutrition and a separate long-run effect of sanitation and health care. In any case, these effects are smaller than half of the effect for areas where both are lacking.

It is possible that the causal pathway from economic conditions to nutritional quality and its interaction with health infrastructure, and their long run effects, is transmitted to some extent through stress at the household level early in life. In this sense the finding in the literature that stress adversely affects the probability of twinbirths (see Subsection 4.1.2) is in line with our finding that twinning rates are slightly lower in recessions. ${ }^{18}$

Some other possible explanations seem less likely. If inferior housing conditions with inadequate heating and crowdedness were a major factor, then one would expect the business cycle effect among those born in Copenhagen to substantially exceed the corresponding effect among those born in rural areas. The same applies to exposure to job loss. In fact, crowdedness seems to have been particularly high in towns in boom years, as many workers from rural areas then migrated temporarily to towns, and epidemics were virtually absent during our

\footnotetext{
${ }^{18}$ Also, Farah, Noble and Hurt (2008) find that poverty in the household leading to stress causes neurological damage among children in the first years of their life, resulting in a lower IQ.
} 
observation window. So, exposure to diseases does not seem to be a primary explanation of our results either.

Finally, if Copenhagen were more heavily exposed to the business cycle than other parts of the country then the cyclical effect should be larger among those born in Copenhagen than among those born elsewhere. The historical literature points out that other towns were as industrialized as Copenhagen.

Recall that most of these considerations are based on results for Zealand and Copenhagen, and that the estimates do not uniformly carry over to the national level. An alternative approach to understand how long-run effects work is by estimating models containing additional macro indicators. We consider national annual time-series data of yearly averages, and we include their transitory (detrended) values as additional explanatory variables in the duration analyses. To capture nutritional mechanisms, we use the deflated prices of wheat, rye, barley, and bacon. Series on other food prices, the national unemployment rate, housing rents, and fuel (coal, oil) prices are only available for a small subset of later years in our birth observation interval, so we do not use these. To capture disease load exposure around birth, we use the infant mortality rate (IMR). We also use weather indicators (temperature, rainfall and cloud cover). Finally, we examine the sex ratio among newborns, since this has been shown to be informative on the stress levels of potential prospective mothers (Catalano et al., 2005). The time-series data are mostly taken from Christensen (1985), Statistics Denmark (1958), Johansen (1985), Mitchell (2003), and Andreev (2002).

It turns out that the additional indicators have small and insignificant effects on the CV mortality rate later in life, ${ }^{19}$ while the business cycle effect itself is insensitive to the inclusion of these indicators. Apparently, these indicators are insufficiently informative as determinants of early-life conditions. There are two possible explanations for this. Consider, in particular, the food price and infant mortality rate. The yearly fluctuations in the indicators are not very large. It may be that the fluctuations in these variables in the late 19th century do not reflect damaging effects on the household's nutrition intake or disease exposure. The household may be able to compensate for moderate price fluctuations of specific food products by way of a temporary substitution towards other food types, and a high disease load may not be reflected by a high IMR. The second explanation is that the national and yearly scales in which the indicators are

\footnotetext{
${ }^{19}$ For the IMR, this result confirms Catalano and Bruckner (2006) who find no significant association between the detrended cohort mortality rate below age 5 and the detrended mean lifetime conditional on survival up to age 5, using Danish aggregate data with annual birth cohorts 1835-1913.
} 
measured smoothen out much variation. Variation within the year may dominate the variation between years. This explanation seems to be confirmed by the finding that season of birth does have significant long-run effects. ${ }^{20}$

\section{Conclusions}

Transitory macro-economic conditions at birth have a significant effect on the cardiovascular mortality rate much later in life. An individual who is born in a recession and who survives until age 40 lives around 11 months shorter than an otherwise identical individual born in a boom, just because the risk of CV mortality is lower. This implies that economic conditions around birth have a negative causal effect on cardiovascular mortality later in life. Or, in other words, high-age mortality due to cardiovascular diseases depends on economic conditions in the first year of life. For cancer-related mortality we do not find long-run effects of early-life conditions.

From spatial variation in the effect we find some evidence that economic conditions early in life exert their influence through nutritional quality and health infrastructure, as opposed to disease load exposure and housing conditions. In particular, the interaction of nutritional quality and health infrastructure seems to be important, in the sense that economic conditions leading to suboptimal early-life nutritional patterns are more harmful in the long run if the health infrastructure early in life is inadequate. However, it is an important topic for further research to study this in more detail, using disaggregated early-life indicators of nutrition, health care, sanitation, disease load exposure, housing conditions, and labor market conditions.

In general, the results for the long-run economic effects on cause-specific mortality rates are in accordance to predictions from the medical and epidemiological literature. As the latter are mostly based on associations between birth weight and health later in life, we feel that the current study provides an important external confirmation of this "developmental origins" literature concerning cardiovascular diseases.

To the extent that long-run effects are driven by relative discrepancies between conditions around birth and later in life, rather than absolute levels of deprivation, the results suggest that it may be efficient to target young individuals born under adverse conditions in developed countries for regular screenings of CVD markers and predictors, and to expose those who have unfavorable test values to preventive

\footnotetext{
${ }^{20}$ For example, Moore et al. (1997) find a long-run effect of being born in the wet season in Gambia on mortality later in life.
} 
interventions. Moreover, the results support investments in nutritional quality and health infrastructure in countries with a high degree of deprivation, as a means to reduce the cardiovascular mortality rate in future years.

The twin feature of the data allows us to assess the extent to which variation in cardiovascular mortality can be attributed to genetic and householdenvironmental factors on the one hand, and individual-specific factors on the other. It turns out that the former factors are more important if the individual is born under adverse economic conditions. Conversely, if the individual in born under better conditions then individual-specific factors dominate more. In short, individual-specific qualities come more to fruition if the starting position in life is better. As the extent to which genetic factors express themselves depends on the environment into which one is born, one may argue that nature and nurture interact in their effect on cardiovascular mortality. This is by no means the first study to report such an interaction. However, by using exogenous indicators of economic conditions early in life, we are at a methodological advantage over studies using family income or social status as an interacting variable for genetic determinants. 


\section{References}

Almond, D.V. (2002), Cohort differences in health: a duration analysis using the National Longitudinal Mortality Study, Working paper, University of Chicago.

Andersen, P.K., Ø. Borgan, R.D. Gill, and N. Keiding (1993), Statistical Models Based on Counting Processes, Springer, New York.

Andreev, K. (2002), Evolution of the Danish Population from 1835 to 2000, University Press of Southern Denmark, Odense.

Barker, D. (2007), The origins of the developmental origins theory, Journal of Internal Medicine 261, 412-417.

Bengtsson, T. and M. Lindström (2000), Childhood misery and disease in later life: The effects on mortality in old age of hazards experienced in early life, southern Sweden, 1760-1894, Population Studies 54, 263-277.

Bengtsson, T. and M. Lindström (2003), Airborne infectious diseases during infancy and mortality in later life in southern Sweden, 1766-1894, International Journal of Epidemiology 32, 286-294.

Ben-Schlomo, Y. (2001), Commentary: Are birthweight and cardiovascular associations due to fetal programming?, International Journal of Epidemiology $30,862-863$.

Black, S.E., P.J. Devereux and K.G. Salvanes (2007), From the cradle to the labor market? The effect of birth weight on adult outcomes, Quarterly Journal of Economics 122, 409-439.

Bortolus, R., F. Parazzini, L. Chatenoud, G. Benzi, M.M. Bianchi and A. Marini (1999), The epidemiology of multiple births, Human Reproduction Update 5, 179-187.

Case, A., M. Lubotsky and C. Paxson (2002), Economic status and health in childhood: The origins of the gradient, American Economic Review 92, 13081334.

Case, A., A. Fertig and C. Paxson (2005), The lasting impact of childhood health and circumstance, Journal of Health Economics 24, 365-389.

Catalano, R., T. Bruckner T. Hartig, and M. Ong (2005), Population stress and the Swedish sex ratio, Paediatric and Perinatal Epidemiology 19, 413-420.

Catalano, R. and T. Bruckner (2006), Child mortality and cohort lifespan: a test of diminished entelechy, International Journal of Epidemiology 35, 1264-1269. 
Christensen, J. (1985), Landbostatistik Håndbog I Dansk Landbohistorisk Statistik 1830-1900, Landbohistorisk Selskab, Copenhagen.

Christensen, K., J.W. Vaupel, N.V. Holm and A.I. Yashin (1995), Mortality among twins after age 6: fetal origins hypothesis versus twin method, British Medical Journal 310, 432-436.

Christensen, K., A. Wienke, A. Skytthe, N.V. Holm, J.W. Vaupel, and A.I. Yashin (2001), Cardiovascular mortality in twins and the fetal origins hypothesis, Twin Research 4, 344-349.

Cutler, D.M., G. Miller and D.M. Norton (2007), Evidence on early-life income and late-life health from America's Dust Bowl era, Proceedings of the National Academy of Sciences 104, 13244-13249.

Doblhammer, G. (2004), The Late Life Legacy of Very Early Life, Springer, Berlin.

Eriksson, J.G. (2007), Epidemiology, genes and the environment: lessons learned from the Helsinki Birth Cohort Study, Journal of Internal Medicine 261, 418425 .

Eriksson, A.W. and J. Fellman (2004), Demographic analysis of the variation in the rates of multiple maternities in Sweden since 1751, Human Biology 76, 343-359.

Farah, M.J., K.G. Noble and H. Hurt (2008), Poverty, privilege, and brain development: empirical findings and ethical implications, Working paper, University of Pennsylvania.

Fellman, J. and A.W. Eriksson (2006), Stillbirth rates in singletons, twins and triplets in Sweden, 1869 to 2001, Twin Research and Human Genetics 9, 260265.

Fogel, R.W. (1997), New findings on secular trends in nutrition and mortality: some implications for population theory, in: M.R. Rosenzweig and O. Stark (eds.), Handbook of Population and Family Economics, North-Holland, Amsterdam.

Galobardes, B., J.W. Lynch and G. Davey Smith (2004), Childhood socioeconomic circumstances and cause-specific mortality in adulthood: Systematic review and interpretation, Epidemiologic Reviews 26, 7-21.

Gluckman, P.D., M.A. Hanson and C. Pinal (2005), The developmental origins of adult disease, Maternal and Child Nutrition 1, 130-141. 
Greasley, D. and J.B. Madsen (2006), A tale of two peripheries: Real wages in Denmark and New Zealand, Scandinavian Economic History Review 54, $116-137$.

Harvald, B. G. Hauge, K. Ohm Kyvik, K. Christensen, A. Skytthe and N.V. Holm (2004), The Danish Twin Registry: past and present, Twin Research 7, $318-335$.

Henriksen, I. and K.H. O'Rourke (2005), Incentives, technology and the shift to year-round dairying in late nineteenth century Denmark, Economic History Review 58, 520-554.

Henriksen, I. (2006), An economic history of Denmark, in: R. Whaples, ed., Economic History.Net Encyclopedia, Economic History Services, Miami.

Herskind A.M., M. McGue, I.A. Iachine, N.V. Holm, T.I. Sørensen, B. Harvald, and J.W. Vaupel (1996), Untangling genetic influences on smoking, body mass index and longevity: a multivariate study of 2464 Danish twins followed for 28 years, Human Genetics 98, 467-475.

Holemans, K., S. Caluwaerts, and F. André Van Assche (2002), Unravelling the fetal origins hypothesis, The Lancet 360, 2073.

Huxley, R., C.G. Owen, P.H. Wincup, D.G. Cook, J. Rich-Edwards, G. Davey Smith and R. Collins (2007), Is birth weight a risk factor for ischemic heart disease in later life?, American Journal of Clinical Nutrition 85, 1244-1250.

Järvelin, M.R., U. Sovio, V. King, L. Lauren, B. Xu, M.I. McCarthy, A.L. Hartikainen, J. Laitinen, P. Zitting, P. Rantakallio and P. Elliott (2004), Early life factors and blood pressure at age 31 years in the 1966 Northern Finland Birth Cohort, Hypertension 44, 838-846.

Johansen, H.C. (1985), Dansk Historisk Statistik 1814-1980, Gyldendal, Copenhagen.

Johansen, H.C. (2002a), Danish Population History 1600-1939, University Press of Southern Denmark, Odense.

Johansen, H.C. (2002b), Denmark - production and communications - trends in employment and trades, in: Denmark, Royal Danish Ministry of Foreign Affairs, Copenhagen.

Kåreholt, I. (2001), The long shadow of socioeconomic conditions in childhood: do they affect class inequalities in mortality?, in: J.O. Jonsson and C. Mills, eds., Cradle to Grave: Life-course Change in Modern Sweden, Sociology Press, Durham. 
Lawlor, D.A. (2008), The developmental origins of health and disease: where do we go from here?, Epidemiology 19, 206-208.

Løkke, A. (2002), Infant mortality in nineteenth century Denmark: regionality, feeding habits, illegitimacy and causes of death, Hygiea Internationalis 3, 115149.

Løkke, A. (2007), State and insurance: the long-term trends in Danish health policy from 1672 to 1973, Hygiea Internationalis 6, 7-24.

McCormack, V.A., I. dos Santos Silva, B.L. De Stavola, R. Mohsen, D.A. Leon, and H.O. Lithell (2003), Fetal growth and subsequent risk of breast cancer: results from long term follow up of Swedish cohort, British Medical Journal $326,248-253$.

McCormack, V.A., I. dos Santos Silva, I. Koupil, D.A. Leon, and H.O. Lithell (2005), Birth characteristics and adult cancer incidence: Swedish cohort of over 11,000 men and women, International Journal of Cancer 115, 611-617.

Mitchell, B.R. (2003), International Historical Statistics: Europe, 1750-2000, Palgrave Macmillan, New York.

Mogren, I., U. Högberg, B. Stegmayr, B. Lindahl, and H. Stenlund (2001), Fetal exposure, heredity and risk indicators for cardiovascular disease in a Swedish welfare cohort, International Journal of Epidemiology 30, 853-862.

Moore, S.E., T.J. Cole, E.M.E. Poskitt, B.J. Sonko, R.G. Whitehead, I.A. McGregor, and A.M. Prentice (1997), Season of birth predicts mortality in rural Gambia, Nature 388, 434.

National Board of Health (1983), Mortality and Causes of Death in Denmark 1931-80, National Board of Health, Copenhagen.

Pollitt, R.A., K.M. Rose and J.S. Kaufman (2005), Evaluating the evidence for models of life course socioeconomic factors and cardiovascular outcomes: A systematic review, BMC Public Health 5:7, 1-13.

Poulter, N.R., C.L. Chang, A.J. MacGregor, H. Snieder and T.D. Spector (1999), Association between birth weight and adult blood pressure in twins: historical cohort study, British Medical Journal 319, 1330-1333.

Rasmussen, K.M. (2001), The "fetal origins" hypothesis: challenges and opportunities for maternal and child nutrition, Annual Review of Nutrition 21, 73-95.

Ruhm, C.J. (2000), Are recessions good for your health?, Quarterly Journal of Economics 115, 617-650. 
Sastry, N. (2004), Trends in socioeconomic inequalities in mortality in developing countries: the case of child survival in Sao Paulo, Brazil, Demography 41, 443464.

Saugstad, L.F. (1999), Optimality of the birth population reduces learning and behaviour disorders and sudden infant death after the first month, Acta Paediatrica Supplement 429, 9-28.

Schmidt, L., U. Christensen and B.E. Holstein (2005), The social epidemiology of coping with infertility, Human Reproduction 20, 1044-1052.

Skytthe, A., K. Kyvik, N.V. Holm, J.W. Vaupel and K. Christensen (2002), The Danish Twin Registry: 127 birth cohorts of twins, Twin Research 5, 352-357.

Statistics Denmark (1902), Statistisk Aarbog 1902, National Statistical Bureau, Copenhagen.

Statistics Denmark (1958), Landbrugets Priser 1900-1957, Statistiske Undersøgelser $n r$. 1, Danmarks Statistik, Copenhagen.

Van den Berg, G.J. (2001), Duration models: specification, identification, and multiple durations, in: J.J. Heckman and E. Leamer (eds.), Handbook of Econometrics, Volume V, North-Holland, Amsterdam.

Van den Berg, G.J., M. Lindeboom and F. Portrait (2006), Economic conditions early in life and individual mortality, American Economic Review 96, 290-302.

Van den Berg, G.J., M. Lindeboom and M. López (2006), Inequality in individual mortality and economic conditions earlier in life, Working paper, VU University Amsterdam.

Vaupel, J.W. and A.I. Yashin (1985), The deviant dynamics of death in heterogeneous populations, in: N.B. Tuma (ed.), Sociological Methodology 1985, Jossey-Bass, San Francisco.

Wienke, A., N.V. Holm, A. Skytthe and A.I. Yashin (2001), The heritability of mortality due to heart diseases: A correlated frailty model applied to Danish twins, Twin Research 4, 266-274.

Wienke, A., K. Christensen, A. Skytthe and A.I. Yashin (2002), Genetic analysis of cause of death in a mixture model of bivariate lifetime data, Statistical Modelling 2, 1-14.

Wienke, A., K. Arbeev, I. Locatelli and A.I. Yashin (2005), A comparison of different bivariate correlated frailty models and estimation strategies, Mathematical Biosciences 198, 1-13. 
Zaretsky, M.D. (2003), Communication between identical twins: health behavior and social factors are associated with longevity that is greater among identical than fraternal U.S. World War II veteran twins, Journal of Gerontology A 58, $566-572$. 
Table 2: Cox-PL parameter estimates of a $\mathrm{PH}$ Model for the individual $\mathrm{CV}$ mortality rate

\begin{tabular}{|c|c|c|c|c|c|c|}
\hline variable & estimate & \multicolumn{2}{|c|}{ parsimonious } & estimate & $\begin{array}{l}\text { extended } \\
\text { (st.error) }\end{array}$ & t-value \\
\hline recession at birth & 0.12 & $(0.037)$ & 3.2 & 0.12 & $(0.037)$ & 3.2 \\
\hline male & 0.33 & $(0.037)$ & 8.9 & 0.34 & $(0.037)$ & 9.0 \\
\hline $\log ($ birth year-1872) & -0.094 & $(0.030)$ & 3.1 & -0.090 & $(0.030)$ & 3.0 \\
\hline season: spring & 0.12 & $(0.043)$ & 2.8 & 0.050 & $(0.052)$ & 1.0 \\
\hline summer & & & & -0.076 & $(0.051)$ & 1.5 \\
\hline winter & & & & -0.14 & $(0.051)$ & 2.7 \\
\hline birth location: Copenhagen & 0.15 & $(0.056)$ & 2.6 & 0.15 & $(0.059)$ & 2.6 \\
\hline town & & & & 0.012 & $(0.051)$ & 0.2 \\
\hline Zealand & & & & 0.014 & $(0.044)$ & 0.3 \\
\hline Funen & & & & 0.012 & $(0.061)$ & 0.2 \\
\hline MZ & -0.039 & $(0.038)$ & 1.0 & -0.041 & $(0.038)$ & 1.1 \\
\hline log partial likelihood & -22496.9 & & & -22493.2 & & \\
\hline
\end{tabular}

Note: in the extended specification, the default birth location is rural in Jutland. 
Table 3: Parameter estimates of Gompertz PH Model for the individual CV mortality rate

\begin{tabular}{lrl}
\hline \hline & & \\
variable & estimate & (t-value) \\
& & \\
recession at birth & 0.12 & $(3.2)$ \\
male & 0.34 & $(9.0)$ \\
log (birth year-1872) & -0.10 & $(3.5)$ \\
spring season & 0.13 & $(2.9)$ \\
Copenhagen & 0.15 & $(2.7)$ \\
MZ & -0.042 & $(1.1)$ \\
\hline
\end{tabular}

Gompertz age dependence $0.000305 \quad$ (100.7) 
Table 4: Parameter estimates of the Correlated Gamma-Frailty Model for the individual CV mortality rate

\begin{tabular}{lrlc}
\hline \hline variable & estimate & (st.error) & t-value \\
covariates & & & \\
& & & \\
recession at birth & 0.14 & $(0.050)$ & 2.8 \\
male & 0.45 & $(0.052)$ & 8.8 \\
log (birth year-1872) & -0.12 & $(0.044)$ & 2.7 \\
spring season & 0.16 & $(0.058)$ & 2.7 \\
Copenhagen & 0.18 & $(0.075)$ & 2.3 \\
MZ & -0.033 & $(0.051)$ & 0.6 \\
& & & \\
\hline & & & \\
Gompertz age dependence & 0.000371 & $(0.00001)$ & 40.5 \\
& & & \\
\hline & & & \\
bivariate frailty distribution & & & \\
& & & \\
variance & 0.49 & $(0.063)$ & 7.9 \\
correlation DZ recession & 0.85 & $(0.17)$ & 5.1 \\
correlation DZ boom & 0.49 & $(0.0085)$ & 57.7 \\
correlation MZ recession & 1 & & \\
correlation MZ boom & 1 & & \\
\hline \hline
\end{tabular}


Table 5: Parameter estimates of models for the individual CV mortality rate with an alternative cyclical indicator or with effects of business cycles around the birth year

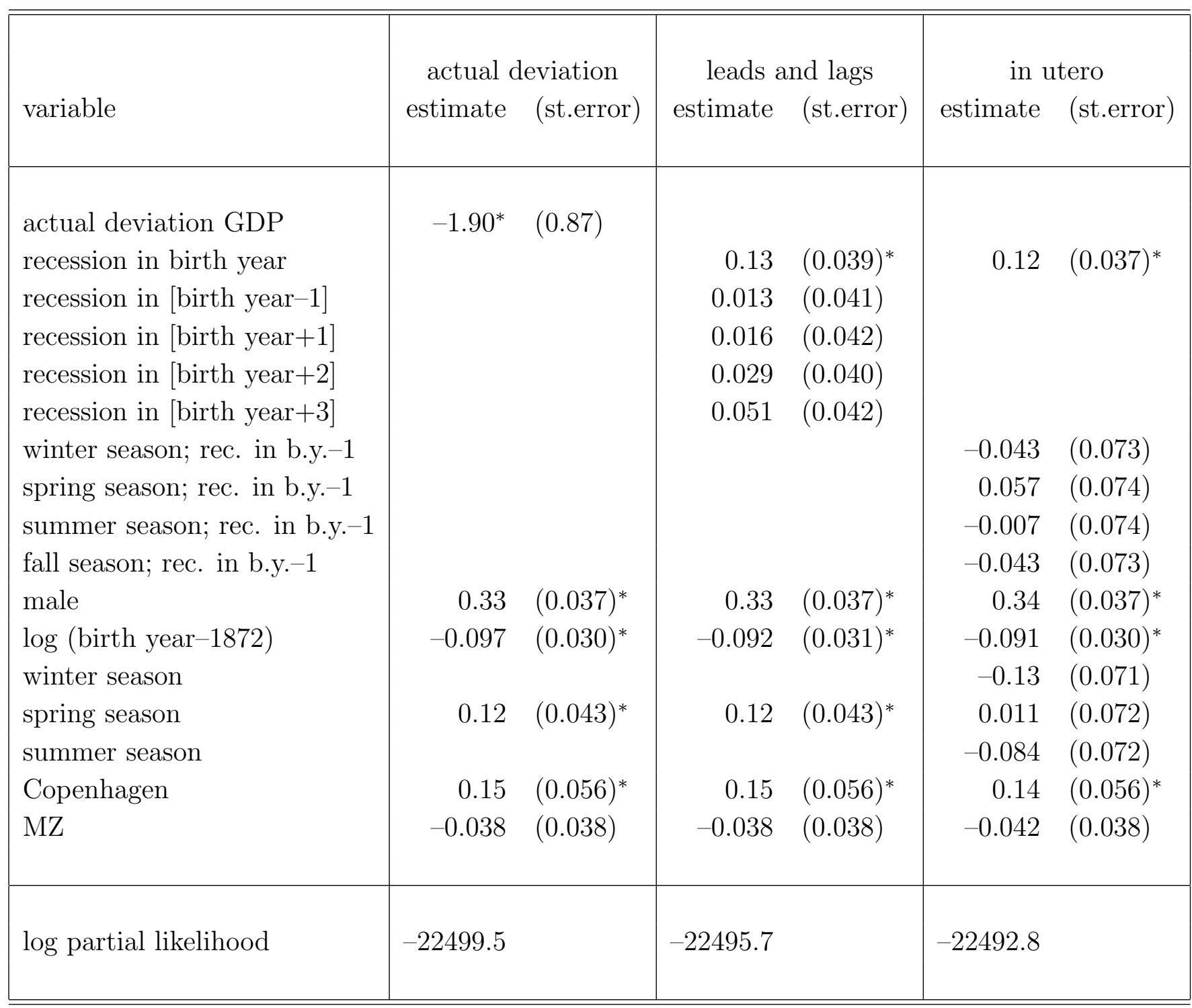

Note: a superindex $*$ indicates significance at the $5 \%$ level. The second column with parameter estimates should be compared to the first column with estimates in Table 2. "Birth year-1" means the year before the birth year, etc. 
Table 6: Parameter estimates for other mortality rates

\begin{tabular}{|l|rl|rl|}
\hline \hline \multirow{2}{*}{ variable } & \multicolumn{2}{|c|}{ all causes } & \multicolumn{2}{c|}{ cancer } \\
& estimate & (st.error) & estimate & (st.error) \\
& & & & \\
recession at birth & 0.093 & $(0.027)^{*}$ & 0.032 & $(0.059)$ \\
male & 0.36 & $(0.027)^{*}$ & 0.30 & $(0.058)^{*}$ \\
log (birth year-1872) & -0.055 & $(0.023)^{*}$ & 0.0085 & $(0.053)$ \\
spring season & 0.12 & $(0.031)^{*}$ & 0.088 & $(0.067)$ \\
Copenhagen & 0.18 & $(0.039)^{*}$ & 0.29 & $(0.081)^{*}$ \\
MZ & -0.059 & $(0.027)^{*}$ & -0.095 & $(0.060)$ \\
& & & & \\
\hline
\end{tabular}

Note: a superindex $*$ indicates significance at the $5 \%$ level.

Table 7: Parameter estimates for the individual CV mortality rate in Zealand incl. Copenhagen with interactions between cyclical and urbanization indicators

\begin{tabular}{lrl}
\hline \hline & & \\
variable & estimate & (st.error) \\
& & \\
recession at birth in Copenhagen & 0.14 & $(0.11)$ \\
recession at birth in town & 0.34 & $(0.16)^{*}$ \\
recession at birth in rural & 0.10 & $(0.082)$ \\
male & 0.38 & $(0.061)^{*}$ \\
log (birth year-1872) & -0.12 & $(0.049)^{*}$ \\
spring season & 0.11 & $(0.071)$ \\
birth location: Copenhagen & 0.13 & $(0.089)$ \\
$\quad$ town & -0.087 & $(0.13)$ \\
MZ & -0.021 & $(0.063)$ \\
& & \\
\hline \hline
\end{tabular}

Notes: a superindex $*$ indicates significance at the $5 \%$ level. The sample is the sub-sample of those born in Zealand incl. Copenhagen (sample size 2262). 